\title{
CRÍTICA À IDEIA DO “CARÁTER PATRIMONIALISTA” DO ESTADO BRASILEIRO: REDUÇÃO DO PODER OLIGÁRQUICO REGIONAL
}

\author{
Elsio Lenardão (Ciências Sociais - UEL)
}

\section{RESUMO}

Predomina, no jornalismo e na academia, a sugestão de que o Estado no Brasil seria regido pelo "patrimonialismo", decorrendo daí, principalmente, os percalços que comprometem o republicanismo e a justiça social no país. Dessa forma, o debate gira em torno dos termos que tal sugestão propõe: privilégios de um suposto "estamento estatal", apropriação privada da coisa pública, corrupção, gigantismo do Estado, interferência do Estado nos negócios privados, domínio das oligarquias políticas etc. Poderíamos denominar tal interpretação de "hipótese patrimonialista". Como resultado parcial de pesquisa em andamento, propomos neste artigo que tal interpretação estaria desatualizada diante das mudanças que atingiram a sociedade e o Estado brasileiros nas últimas três décadas, ao menos. Entre essas alterações, teríamos: a) uma mudança no modelo econômico que teria provocado deslocamentos de grupos no bloco no poder, principalmente por meio das privatizações de empresas e bancos estatais e de superintendências regionais; e b) o aumento da competição eleitoral no país, com maior número de eleitores e de candidatos. Tais mudanças teriam reduzido a relevância das oligarquias políticas regionais na ocupação de espaços no aparelho de Estado, impactando no enfraquecimento da "hipótese patrimonialista", já que essas oligarquias são portadoras de fortes componentes patrimonialistas no seu comportamento político.

Palavras-chave: Estado brasileiro; Patrimonialismo no Brasil; Oligarquias regionais.

\section{INTRODUÇÃO}

Vivemos numa sociedade patrimonialista e, portanto, oligárquica. [Temos um] Estado patrimonialista, oligárquico até à medula. ${ }^{1}$

O Brasil do século 21 vive a mesma crise política estrutural do início do século 20. Cem anos, seis constituições e duas ditaduras depois, as aparências mudaram, mas as essências seguem: oligarquias regionais dominam os Estados mais pobres e juntas impõem seu controle sobre o poder central. $^{2}$

O Brasil, sabemos, é controlado, desde quando foi colônia portuguesa, por oligarquias regionais. (...) a política do Brasil, hoje, ainda registra a existência das poderosas oligarquias regionais, representadas no Parlamento Nacional. Elas também controlam os Parlamentos dos

\footnotetext{
${ }^{1}$ FERNANDES, Bob. Os donos do poder. Revista Carta Capital, n. 13, ago. 1995, p. 16.

2 SERVA, Leão. Jucá e a sombra de Sarney. Folha de S. Paulo. 30 jun. 2014. Disponível em: http:www1.folha.uol.com.br/colunas/leaoserva/2014/06/1478585-juca-e-a-sombra-de-sarney.shtml. Acesso em: 30/06/2014.
} 


\section{SEMINÁRIO DE PESQUISA EM CIÊNCIAS HUMANAS - SEPECH \\ Humanidades, Estado e desafios didático-científicos \\ Londrina, 27 a 29 de julho de 2016}

estados e os seus poderes executivos. Elas são muito fortes no Judiciário, tanto em plano federativo quanto nos estados. ${ }^{3}$

As epígrafes acima ilustram a reiteração na mídia, na opinião pública e em parte importante da academia, de uma interpretação a respeito do Estado brasileiro que goza de grande unanimidade. Ela sugere que o Estado no Brasil seria, ainda hoje, regido pelo "patrimonialismo". Essa interpretação costuma indicar, na forma de denúncia, que o Estado brasileiro se põe, ora: a) como patrimônio "possuído" por segmentos do funcionalismo público - que se comportariam à semelhança de estamentos -; b) ora, como possuído por agentes ou grupos políticos (que costumam ser identificados como "classe política" ou "oligarquias políticas") que ocupam ocasionalmente cargos no aparelho de Estado.

Aparece também entre essa versão a indicação de que o caráter patrimonialista do Estado brasileiro se revelaria pelo fato de ele ser "tomado", direta ou indiretamente, por pequenos grupos ou setores restritos da elite empresarial brasileira que moveriam seus negócios a base de subsídios, benesses ou a base de relações escusas com o Estado. Por fim, acusa-se este traço, o do patrimonialismo, de ser o grande responsável pelos dramas e percalços que comprometem a realização do republicanismo e da justiça social no país. Pode-se denominar o conjunto das interpretações expostas acima sobre o Estado brasileiro e sobre seu funcionamento como "hipótese patrimonialista". 4

Parece acompanhar a "hipótese patrimonialista", a ideia de que nada mudou nos últimos anos quanto à organização e ao funcionamento do Estado brasileiro. Porém, é possível sugerir que tal interpretação, considerando seus pressupostos básicos, tanto aqueles de caráter teórico quanto histórico, estaria desatualizada diante das mudanças que atingiram a sociedade e o Estado brasileiros nas últimas três décadas, ao menos.

Poderiam ser tomados como exemplos dessas alterações: a) o crescimento e fortalecimento da capacidade dos movimentos sociais de base popular e de outros segmentos da sociedade civil de influenciar e exercer certo controle sobre alguns programas e políticas estatais, em especial, participando de Conselhos de Gestão (como Conselhos de Assistência Social, de Saúde, de Educação); b) mudanças no modelo econômico, nos anos 1990 e início dos anos 2000, que teriam provocado deslocamentos de grupos e frações de classe no bloco no poder, principalmente por meio das privatizações de empresas e bancos estatais e de superintendências regionais, que afetaram a capacidade das oligarquias políticas regionais distribuírem favores a suas clientelas, reduzindo a relevância que antes possuíam na ocupação de espaço no aparelho de Estado; c) a reforma administrativa do Estado empreendida nos anos 1990 e sua "modernização" (por exemplo, a consolidação do ingresso no quadro do funcionalismo por meio de concurso público, ampliando os espaços de autonomia relativa da burocracia, amparada em procedimentos de racionalização e impessoalização).

Destacam-se, ainda, o reforço de mecanismos de racionalização e transparência no uso dos recursos públicos, como a instituição da Lei de Responsabilidade Fiscal, da Lei anticorrupção, da Lei da Transparência, o aprimoramento da Lei de Licitações;

\footnotetext{
${ }^{3}$ Editorial da revista Educação e Sociedade, vol. 23, n. 81, dez. 2002.

${ }^{4} \mathrm{O}$ texto clássico que sugere a hipótese do patrimonialismo é Os donos do poder, de Raymundo Faoro (1989).
} 


\section{SEMINÁRIO DE PESQUISA EM CIÊNCIAS HUMANAS - SEPECH \\ Humanidades, Estado e desafios didático-científicos \\ Londrina, 27 a 29 de julho de 2016}

mudanças, impostas pela Constituição de 1988, na forma de financiamento e gestão de certas políticas públicas, com a definição da aplicação obrigatória de porcentuais mínimos dos recursos orçamentários destinados a algumas áreas sociais, por meio do instrumento do orçamento vinculado ${ }^{5}$; alterações no sistema judiciário com a implantação das promotorias de defesa do patrimônio público, valorização da atuação da Controladoria Geral da União (CGU) na fiscalização da aplicação dos recursos federais; e, não menos relevante, o crescente comprometimento de parte significativa do fundo público com o pagamento de juros e amortizações de dívidas do governo federal, por meio da produção de superávits primários, ${ }^{6}$ o que teria "forçado" o Estado brasileiro a racionalizar seus gastos, reduzindo o montante sujeito à distribuição clientelística, para economizar recursos visando os compromissos com tais dívidas.

A posição proposta no presente artigo faz parte de pesquisa em andamento ${ }^{7}$ que trabalha com a hipótese de que talvez seja exagerado referir-se à vigência de uma "estrutura estatal de tipo patrimonialista" no Brasil de hoje. Sugere-se que mudanças importantes ocorridas nos últimos anos na sociedade e no Estado brasileiros levam a que se relativize a "hipótese patrimonialista"; por exemplo, que se atenue argumentos como o de que a política brasileira e o "poder político central" seriam controlados pelas oligarquias políticas regionais. ${ }^{8}$

Neste artigo, será problematizada a centralidade que a grande maioria daqueles que recorrem à noção de patrimonialismo para analisar o Estado e a política brasileira costuma dar à suposta presença das "oligarquias regionais" no controle e mando do Estado. Por certo que a política brasileira atual e a ação do Estado no país são marcadas pela influência oligárquica. A questão aqui, neste trabalho, é esclarecer se o alcance desta influência vem se alterando nas últimas três décadas. Isto é, verificar alguns dos aspectos que vêm organizando, ultimamente, a interação entre políticos, eleitores e burocracia pública (aparelhos do Estado) e como esses aspectos impactam na força de influência das oligarquias políticas regionais sobre o Estado brasileiro.

A observação dos impactos sociais e políticos das mudanças anotadas acima permitiria tratar esses aspectos patrimonialistas (corrupção, fisiologismo, nepotismo, apossamento privado de bens públicos, presença de oligarquias regionais etc.) como práticas que sobrevivem na política e no Estado brasileiros, mas que não definem seu caráter. Tais práticas mantêm-se como acomodadas e, muitas vezes, até funcionais a

\footnotetext{
${ }^{5}$ Um exemplo de vinculação do orçamento é o da Emenda Constitucional $n^{0} 29$, que fixa os gastos obrigatórios do governo federal, dos estados e dos municípios com o sistema público de saúde.

${ }^{6}$ Refere-se à economia que os governos federal, estadual e municipal realizam, excluindo o gasto com juros da dívida, para cumprir compromissos de pagamentos dos juros e amortização da dívida pública.

${ }^{7}$ Parte do que já foi realizado pela pesquisa pode ser visto em LENARDÃO (2012); (2015).

${ }^{8} \mathrm{O}$ termo "oligarquia" vem sendo utilizado para qualificar aqueles agrupamentos políticos que em boa parte dos casos se baseiam em laços familiares e que se destacam pela força política regional (capacidade de influência e ocupação de espaços no aparelho estatal) e pela longevidade de sua presença na arena política. Às vezes, por causa da linhagem, são tomados por "clãs" políticos. As oligarquias políticas regionais são comumente consideradas portadoras de fortes componentes patrimonialistas e personalistas no seu comportamento político. Uma lista das oligarquias famosas no cenário político recente do país incluiriam, por exemplo, os Jereissati, do Pará, os Magalhães, na Bahia, os Barbalho, no Pará, Os Sarney, no Maranhão, os Collor, em Alagoas, os Alves e Maia, no Rio Grande do Norte, os Konder/Bornhausen, em Santa Catarina. Parte dessas oligarquias detêm grandes recursos fundiários e o controle de mídias locais e regionais. Uma excelente exposição de algumas das principais oligarquias regionais brasileiras pode ser vista em FERNANDES (1995).
} 


\section{SEMINÁRIO DE PESQUISA EM CIÊNCIAS HUMANAS - SEPECH \\ Humanidades, Estado e desafios didático-científicos \\ Londrina, 27 a 29 de julho de 2016}

uma estrutura de organização estatal que está muito mais para liberal do que para patrimonialista. ${ }^{9}$

\section{A DIMINUIÇÃO DO PODER POLÍTICO DAS OLIGARQUIAS REGIONAIS}

Pode-se sugerir, conforme Oliveira (2001; 2009), que a partir dos anos 1990 teria ocorrido redução do poder das oligarquias políticas regionais em razão, principalmente, da diminuição da sua presença na ocupação de espaços nos aparelhos de Estado, como consequência do acentuado processo de privatização de empresas, bancos e agências estatais. ${ }^{10}$ Essa suposta redução da influência das oligarquias regionais expressaria modificações importantes na composição do bloco no poder $^{11}$ que se consolida no período.

Nos anos 1990 firma-se, no cenário mundial, o que Chesnais (2005) caracterizou como "financeirização da acumulação capitalista". Nesse quadro, “(...) os países periféricos não são mais vistos primordialmente como oportunidades para investimentos produtivos, mas como plataformas de valorização financeira, recebendo então a denominação de "mercados emergentes"” (TEIXEIRA e PINTO, 2012, p. 917). A nova forma de dependência que vai se consolidando no período implica em uma também nova

(...) articulação entre o sistema econômico e o político e entre as classes e grupos domésticos e externos. Nesse sentido, a fração bancáriofinanceira do capital (bancos, seguradoras, fundos de pensão, corretoras, agências de rating etc.) passa a deter a hegemonia no interior do bloco no poder e sua influência a expressar-se especialmente a partir de um dos principais centros de poder no Estado: o banco central. (...)

\footnotetext{
${ }^{9}$ Quanto a esse aspecto, o do caráter liberal do Estado brasileiro, ver LENARDÃO (2012).

${ }^{10} \mathrm{O}$ comentário de um jornalista da Folha de S. Paulo a respeito da privatização do sistema de telefonia no Brasil resume bem os impactos da privatização, nessa área, sobre o uso político da antiga estatal responsável por esse serviço: "A privatização do sistema Telebrás rendeu ao ex-presidente Fernando Henrique Cardoso muita crítica antes, durante e depois do programa. De aliados e de opositores. Algumas eram procedentes. (...) Outras escondiam a defesa de interesses corporativos e pessoais. Sobre essas, lembro de um desabafo de FHC na época: 'É chiadeira de quem vai perder uns cem cargos políticos'. Diretorias das teles faziam parte das jóias da coroa. Presentes em todos os Estados, eram cobiçadas pelos políticos pelo potencial eleitoral. Rendiam negócios milionários, um canal para a coleta de doações eleitorais e outros negocinhos. Serviam ainda para ganhar votos, prestando serviços como a instalação de telefones a eleitores. A farra acabou com a venda da Telebrás. Taí uma grande serventia das privatizações. Estreitar ao máximo o espaço dentro do Estado utilizado para o jogo político pessoal e eleitoral. Afinal, ninguém se esbofeteia por cargos pensando em um projeto de país" (CRUZ, Valdo. Boquinha livre. Folha de S. Paulo, 22 maio 2005, p. A2).

${ }^{11} \mathrm{O}$ conceito de "bloco no poder" toma em conta, no caso da sociedade capitalista, "(...) a classe burguesa como a unidade (classe social) do diverso (frações de classe) nas suas relações com o Estado e com o restante da sociedade. (...) O emprego do conceito de bloco no poder exige, em primeiro lugar, que o pesquisador detecte as frações da classe dominante que agem como força social distinta em uma dada conjuntura, isto é, os interesses econômicos setoriais burgueses que ensejam, diante da política de Estado, a formação de grupos diferenciados que perseguem, no processo político, objetivos próprios. Em segundo lugar, exige que o pesquisador procure esclarecer quais interesses de fração são priorizados pela política econômica do Estado e quais são relegados a um plano secundário. A localização dos interesses efetivamente priorizados pela política do Estado indica qual é a fração hegemônica no interior do bloco no poder" (BOITO JR., 2007, p. 58-59).
} 


\section{SEMINÁRIO DE PESQUISA EM CIÊNCIAS HUMANAS - SEPECH \\ Humanidades, Estado e desafios didático-científicos \\ Londrina, 27 a 29 de julho de 2016}

Destaque-se, ainda, a solidariedade ideológica e de interesses do mercado financeiro doméstico e do mercado financeiro internacional. Este último, inclusive, pelo apoio decisivo das instituições-chave do sistema financeiro internacional. O Banco Mundial e o FMI, que impunham as políticas ortodoxas ao Brasil e outras economias por meio das condicionalidades exigidas aos empréstimos e socorro às crises nos países periféricos (TEIXEIRA e PINTO, 2012, p. 917).

Nos anos 1990 e início dos anos 2000, os grupos ligados ao mercado financeiro doméstico e internacional ${ }^{12}$ exerceram um poder enorme na condução das macropolíticas nacionais, tanto econômicas como sociais, em prejuízo dos interesses dos trabalhadores do setor privado, do funcionalismo público (com a sugestão de Estado mínimo para as políticas sociais) e até mesmo de alguns grupos da burguesia doméstica ligada ao setor produtivo (por exemplo, com políticas de juros altos) (BOITO Jr., 2002; 2007). Na síntese de Boito Jr. (2011),

No interior do bloco no poder, a primeira coisa a destacar é a hegemonia política do grande capital financeiro, hegemonia política que se mantém ao longo de todo o período neoliberal, do governo Collor ao governo Lula. Isso significa dizer que a política econômica e social do Estado brasileiro ao longo das décadas de 1990 e 2000, atende, prioritariamente, os interesses dos investidores nacionais, articulando e subordinando os interesses das demais frações burguesas aos interesses das finanças (p. 272). (grifos do autor)

\section{Corroborando a interpretação anterior, SAES (2001) observa que}

[a] década de 1990 marca a passagem da economia brasileira a uma nova fase. Nessa fase, reiteram-se, por um lado, as suas características de economia capitalista, monopolista e dependente. Por outro lado, nela se processa uma redefinição do peso econômico dos diferentes setores capitalísticos: o capital monopolista estatal e o capital monopolista privado nacional tendem a perder poder econômico (o primeiro, por meio da privatização; o segundo, por meio da desnacionalização) em benefício do capital monopolista estrangeiro (meramente industrial ou financeiro). Redefine-se portanto, na década de 1990, a direção do desenvolvimento capitalista no Brasil. A essa redefinição, corresponde, no plano político, uma nova organização interna de interesses capitalistas que exerce, desde 1964, a hegemonia no seio do bloco no poder (p. 129).

O capital bancário-financeiro assume, embora na forma de condomínio com as frações do grande capital industrial nacional e estrangeiro e com a dos grandes proprietários rurais, o papel dirigente no seio do bloco no poder e atua na implantação

\footnotetext{
${ }^{12}$ Os chamados "rentistas" atuantes no setor financeiro brasileiro em 2013, por exemplo, eram estimados em algo próximo a "(...) 22 mil famílias ampliadas e grandes bancos e corporações, em sua maioria estrangeiros" (BAVA, 2013).
} 


\section{SEMINÁRIO DE PESQUISA EM CIÊNCIAS HUMANAS - SEPECH \\ Humanidades, Estado e desafios didático-científicos \\ Londrina, 27 a 29 de julho de 2016}

de um modelo de organização político-econômico conhecido como neoliberalismo. ${ }^{13}$ Por certo que sua direção não se dá sem tensões, já que as demais frações integrantes do bloco condicionam sua subordinação ou apoio à preservação de, ao menos, parte de seus interesses específicos (SAES, 2001, p. 131). Por exemplo, o apoio ao projeto neoliberal por parte dos grandes proprietários fundiários estava vinculado à garantia de que não se sacrificaria o sistema estatal vigente de subsídios, de créditos, de suspensão de dívidas etc. voltados à agricultura (leia-se: à grande propriedade). ${ }^{14}$

Quanto à posição dos "velhos" caciques oligárquicos no "condomínio" do poder, no período em discussão, foi emblemática da nova configuração do domínio político a frase marcante proferida pelo Deputado Severino Cavalcanti (típico representante das oligarquias nordestinas), na ocasião presidente da Câmara dos Deputados, num encontro com Lázaro Brandão, dono do banco Bradesco. Em sua abordagem, o Deputado se referia à sugestão de que ele, um "coronel", ocupava a presidência da Câmara de Deputados, mas quem de fato "controlava" o Estado, submetendo o conjunto das macropolíticas estatais aos seus interesses gerais, era, principalmente, a fração financeira e bancária da burguesia.

'Aahh! Esse aqui é o dono do Brasil. Ele manda no Brasil', disse Severino ao ser apresentado a Lázaro Brandão, presidente do Bradesco, nos jardins da casa de Flávio Rocha, da [rede de lojas] Riachuelo, no Jardim América. Severino segurou por longos segundos as mãos de Brandão. 'Preciso de seus conselhos.' Brandão retribuiu. 'É uma grande honra para nós. Você precisa ir lá no banco almoçar. ${ }^{15}$

\section{O IMPACTO DAS PRIVATIZAÇÕES NO PODER POLÍTICO-ECONÔMICO DAS OLIGARQUIAS REGIONAIS}

O processo intenso de privatizações ocorreu na década de 1990, com a criação do Programa Nacional de Desestatização (PND). No início, o PND priorizou a venda de estatais produtivas ligadas às áreas de siderurgia, fertilizantes e petroquímica. Já entre 1991 e 1992 haviam sido privatizadas 18 empresas desses setores. Em seguida o programa ampliou-se com a inclusão de concessões de serviços públicos à iniciativa privada, referentes aos setores de eletricidade $\mathrm{e}$ às áreas de transportes e telecomunicações. Também entrou no rol das privatizações uma série de empresas e bancos estaduais. Desse modo, até janeiro de 2002, 68 empresas tinham sido desestatizadas (REGO e MARQUES, 2006, p. 219), movimentando com as vendas um valor próximo a US\$ 100 bilhões (FRANCO, 2000, p. B1).

Dessa forma o processo de privatizações teria implicado uma significativa transferência de patrimônio e de propriedade entre as frações de classe no Brasil. Segundo Oliveira $(2001 ; 2007), 30 \%$ do PIB brasileiro teria mudado de mãos. Isso

\footnotetext{
${ }^{13}$ Para uma compreensão de como, no pós-64, o "capital bancário" vai progredindo suas posições no bloco no poder, ver SAES, 2001, p. 49-70.

${ }^{14}$ Uma compreensão detalhada das tensões e resistências que o projeto neoliberal encetou, nos anos 1990, no campo político conservador, pode ver vista em SAES, 2001, p. 81-91.

${ }^{15}$ BERGAMO, Mônica. Os donos do Brasil. Folha de S. Paulo. Caderno Ilustrada. 16 mar. 2005, p. E2.
} 


\section{SEMINÁRIO DE PESQUISA EM CIÊNCIAS HUMANAS - SEPECH \\ Humanidades, Estado e desafios didático-científicos \\ Londrina, 27 a 29 de julho de 2016}

trouxe consequências ao quadro do poder, com alterações na correlação de forças dentro do bloco no poder.

Com as privatizações teria havido um acentuado enfraquecimento da capacidade clientelista, tanto do governo federal quanto das oligarquias regionais. É sabido, por exemplo, que a maior parte das empresas, bancos e agências estatais (como as Superintendências SUDENE e SUDAM) era terreno de influências dividido entre grupos políticos estaduais e regionais, conhecidos como oligarquias e famosas pelas práticas de tipo patrimonialista. Na época, o presidente Fernando Henrique Cardoso, diante das resistências dos clãs políticos às privatizações, teria comentado: "É chiadeira de quem vai perder uns cem cargos políticos". Quer dizer, uma dimensão relevante da força das oligarquias regionais e estaduais se assentava no controle de agências e bancos estatais e no uso político de seus recursos financeiros, de empregos e de negócios.

As privatizações dos anos 1990 teriam retirado das mãos dessas oligarquias uma das maiores fontes de sua influência e força política. Oliveira (2009) se refere a essa perda de poder político por parte das oligarquias citando os seguintes exemplos: "Só com as privatizações, ACM (Antônio Carlos Magalhães) perdeu a capacidade de influir em centenas de postos executivos nas empresas que se constituíram orbitando a Petrobrás; Sarney talvez só consiga emplacar alguns Office-boys na Vale do Rio Doce e [Jader] Barbalho tem que se concentrar com a produção de rãs" (p. 5). ${ }^{16}$

Uma das maneiras de as oligarquias espraiarem e alargarem o alcance de sua influência seria por meios do apadrinhamento na indicação de nomes para a ocupação de postos-chave na burocracia estatal. Espera-se, nestes casos, que tais funcionários indicados e seus subordinados agissem como delegados ou despachantes dos interesses dos políticos padrinhos. Com as privatizações retira-se das oligarquias regionais não apenas recursos financeiros. Retira-se também oportunidades de controle e influência sobre parte da burocracia estatal.

Nessa direção, somou-se às privatizações, um processo de consolidação da profissionalização (incremento da impessoalização e da competência nos procedimentos) da burocracia estatal brasileira, demonstrado na definição do concurso público como mecanismo de entrada para o funcionalismo ${ }^{17}$. Esses dois processos, inevitavelmente, impactaram na diminuição dos espaços de influência política das oligarquias sobre os aparelhos de Estado e sobre a burocracia estatal.

\section{A REDUÇÃo DO DOMÍNIO OLIGÁRQUiCO POR MEIO DA COMPETIÇÃO ELEITORAL}

\footnotetext{
${ }^{16}$ Jader Barbalho há tempos pertence e comanda um clã político no Pará. Nos anos de 2001 e 2002, então senador da república, foi acusado de desvios de recursos do Banpará, banco estadual sob sua influência política, e da SUDAM (Superintendência de Desenvolvimento da Amazônia), agência estatal que também esteve, por longa data, sob o controle de seu grupo político. Por exemplo, em 2001 foi revelado que a SUDAM havia "dado" R\$ 9,6 milhões para a esposa de Jader Barbalho tocar um projeto de criação de rãs (Folha Online. Veja a cronologia do caso Jader. Disponível em http://www1.folha.uol.com.br/folha/brasil/ult96u25418.shtml. Acesso em: 19/02/2002.

${ }_{17}$ Para o tratamento da relevância dessa mudança para o questionamento da hipótese patrimonialista, ver LENARDÃO (2015).
} 


\section{SEMINÁRIO DE PESQUISA EM CIÊNCIAS HUMANAS - SEPECH \\ Humanidades, Estado e desafios didático-científicos \\ Londrina, 27 a 29 de julho de 2016}

Embora controversa quanto às suas consequências, outra mudança no espectro político recente que teria afetado o poder político das oligarquias regionais teria sido o aumento da competição eleitoral no país, com a

(...) criação de gigantesco mercado de votos [que] foi acompanhada por crescente competitividade, o que implica, no caso, redução do poder do mandonismo local. Esse tem sido o resultado histórico mais importante da obrigatoriedade do voto (SANTOS, 2003, p. 40).

Números referentes à participação político-eleitoral dos últimos anos no Brasil mostram uma ampliação real da participação eleitoral. Quer dizer, tem-se um maior envolvimento dos cidadãos na vida eleitoral. Por exemplo, em 1945, 23,9\% dos adultos compareceram às urnas. Em 1998, o contingente foi para 78,3\% (NICOLAU, 2002, p. 280). Já em 2014, nas eleições para deputado federal, por exemplo, a participação chegou a $80 \% .^{18}$

Destaca-se nesse quadro que, pelos registros de casos de compra de voto ou de coação ao voto, pode-se facilmente confirmar a impressão de que, atualmente, a maioria absoluta dos eleitores brasileiros demonstra plena autonomia na escolha de seus candidatos, reduzindo-se muito a prática do "voto de cabresto" ou o "voto cativo", típicos do coronelismo. Tal traço se apresenta também na verificação das consideráveis taxas de renovação da representação política nas casas legislativas. Informações apresentadas por SANTOS (2006, p. 233) e SCHOENSTER (2016) sobre a renovação na composição da representação na Câmara dos Deputados mostram que depois da Constituição de 1988 a taxa de renovação está entre 40\% e 50\%. Daí que os resultados eleitorais parecem ser cada vez mais imprevisíveis e fora do controle das oligarquias locais e regionais.

Conforme SANTOS (2006),

É evidente que um eleitorado de tal magnitude não consentiria ser inteiramente controlado como o foram os eleitorados de todos os países, inclusive o Brasil, antes da universalização do voto (e até, em alguns, depois da universalização), isto é, mediante corrupção (compra de votos), intimidação (em áreas nas quais os chefes políticos, sendo também os comandantes econômicos, mantinham praticamente monopólio na oferta de emprego) e favores pessoais. Isso sempre fez parte dos recursos de competição política durante os tempos oligárquicos, em que o eleitorado rural era esmagadoramente superior ao eleitorado urbano em que o número de candidatos era reduzido, tratando-se mais de competição entre clãs familiares do que entre partidos cuja base fosse constituída por cidadãos anônimos. (...) Destruíra-se pouco a pouco o oligopólio da oferta de emprego, com a urbanização e a industrialização, e políticos oligárquicos não se sustentam diante de eleitorados de massa razoavelmente autônomos (p. 220).

Outro dado importante que revela a crescimento da competição eleitoral no Brasil diz respeito ao número de candidatos às vagas legislativas. O número médio de

\footnotetext{
${ }^{18}$ Dados disponíveis em: http://www.tse.jus.br/eleicoes/estatisticas/estatisticas-eleitorais-2014-eleitorado.
} 


\section{SEMINÁRIO DE PESQUISA EM CIÊNCIAS HUMANAS - SEPECH \\ Humanidades, Estado e desafios didático-científicos \\ Londrina, 27 a 29 de julho de 2016}

candidatos por vaga, por eleição no Brasil, à Câmara dos Deputados, por exemplo, evoluiu de 3,5 em 1950 para 9,2 em 2002 e em 2014 foi de 13,91. ${ }^{19}$ Já o número médio de candidatos às Assembleias Legislativas estaduais progrediu de 1,6 em 1950 para 12,2 em 2002 (SANTOS, 2003, p. 40), chegando em 2014 a 16,43. ${ }^{20}$

Com uma legislação que facilita a criação de partidos, com o sistema de eleição proporcional com lista aberta e como são poucas as restrições legais para que alguém seja candidato, vê-se que, pela profusão numerosa e idiossincrática de candidatos nas eleições, têm-se no Brasil elementos que tornam mais frágeis as tentativas de oligarquização ou de protecionismo no sistema partidário, embora não as elimine. Some-se a esses fatores, a) o papel importante na democratização dos processos eleitorais desempenhado pela propaganda eleitoral gratuita, que permite aos partidos o acesso direto ao eleitor, sem mediação de caciques regionais ou de coronéis locais e; $b$ ) o financiamento público de campanhas eleitorais, ainda que parcial, por enquanto, o que permitiria a alguns partidos uma submissão menor à influência do poder econômico e midiático dos caciques regionais e dos coronéis locais.

Por último, ressalve-se que, apesar da razoabilidade do argumento de que a competição eleitoral dilui e enfraquece o controle eleitoral e político exercido pelas oligarquias, parte dos clãs políticos tem conseguido reproduzir-se eleitoralmente (SCHOENSTER, 2016) e manter presença em cargos no aparelho de Estado. Atente-se, no entanto, que o ponto central sugerido neste artigo diz respeito à provável redução da capacidade atual (poder político) de essas oligarquias darem o tom determinante às macropolíticas estatais, dado que ocupam posição subordinada no condomínio de poder em vigência.

\section{CONCLUSÃO}

É provável que nos últimos decênios no Brasil, a presença das oligarquias políticas regionais parasitando o Estado brasileiro, embora maléfica, não seria, de fato, o principal problema do Estado e da sociedade. Por exemplo, a exposição recente de mega casos de corrupção mostra um novo (nem tão novo assim) agente principal nas transações parasitárias com o Estado e não são as oligarquias. São empresários (caso da lava jato) ${ }^{21}$ e banqueiros (caso da Zelotes) ${ }^{22}$. São "novos" atores, dentro do atual bloco

\footnotetext{
${ }^{19}$ Dados disponíveis em: http://www.tse.jus.br/eleicoes/estatisticas/estatisticas-eleitorais-2014-eleitorado.

${ }^{20}$ Dados disponíveis em: http://www.tse.jus.br/eleicoes/estatisticas/estatisticas-eleitorais-2014-eleitorado.

21 A operação Lava Jato refere-se a uma investigação de corrupção e lavagem de dinheiro no Brasil. Estima-se que o volume de recursos desviados dos cofres da Petrobras, empresa envolvida no caso, esteja na casa de bilhões de reais. Nesse esquema, grandes empreiteiras organizadas em cartel pagavam propina para altos executivos da estatal e outros agentes públicos. O valor da propina variava de $1 \%$ a $5 \%$ do montante total de contratos bilionários superfaturados. Disponível em: http://avajato.mpf.mp.br/entendao-caso. Acesso em: 07/05/2016.

${ }^{22}$ A Operação Zelotes da Polícia Federal investiga um dos maiores esquemas de sonegação fiscal já registrados no país. Quadrilhas atuavam, em nome de grandes empresas, junto ao CARF (Conselho Administrativo de Recursos Fiscais), órgão ligado ao Ministério da Fazenda, revertendo ou anulando multas por sonegação. Inicialmente, estariam sob suspeita 74 processos do CARF que somam R\$ 19 bilhões devidos ao fisco. Apresentam-se envolvidas, entre outras empresas, o Grupo Gerdau, a RBS (afiliada da Rede Globo no Rio Grande do Sul), a Ford, a Mitsubishi, os bancos Santander, Safra, Bradesco e Boston. Disponível em: http://www1.folha.uol.com.br/mercado/2015/04/1611246-entenda-aoperacao-zelotes-da-policia-federal.shtml. Acesso em: 07/04/2016.
} 


\section{SEMINÁRIO DE PESQUISA EM CIÊNCIAS HUMANAS - SEPECH \\ Humanidades, Estado e desafios didático-científicos \\ Londrina, 27 a 29 de julho de 2016}

no poder, no quadro das várias formas de se sacrificar o caráter público do Estado, privatizando-o.

\section{REFERÊNCIAS}

BAVA, Silvio Caccia. O nó do desenvolvimento. Disponível em: http://www.diplomatique.org.br/editorial.php?edicao=70. Acesso em: 20/11/2013.

BOITO Jr., Armando. Neoliberalismo e relações de classe no Brasil. Campinas, Idéias, n. 9 (1), 2002, p. 13-48.

BOITO JR., Armando. Estado e burguesia no capitalismo neoliberal. Sociologia e política. n. 28 , jun. 2007, p. 57-73.

BOITO Jr. As relações de classe na nova fase do neoliberalismo no Brasil. Disponível em: http://biblioteca.clacso.edu.ar/clacso/gt/20101020012032/caetano.pdf . Acesso em: $16 / 05 / 2011$.

CHESNAIS, F. O capital portador de juros: acumulação, internacionalização, efeitos econômicos e políticos. In: CHESNAIS, F. (org.). A finança mundializada. São Paulo: Xamã, 2005.

FAORO, Raymundo. Os donos do poder: formação do patronato político brasileiro. São Paulo: Globo, 1989.

FRANCO, Carlos. Brasil privatiza US\$ 100 bilhões em dez anos. O Estado de S. Paulo. Caderno Economia, 30 nov. 2000, p. B1.

FERNANDES, Bob. Os donos do poder: a oligarquia à brasileira e a reforma impossível. Revista Carta Capital, n. 13, ago. 1995. p. 14-59.

LENARDÃO, Elsio. O alcance e os limites da hipótese do caráter patrimonialista do Estado brasileiro: crítica à ideia de estamento estatal. In: LIMA, Angela Maria de Souza (org.). Sugestões didáticas de ensino de Sociologia. Londrina: EDUEL, 2012.

LENARDÃO, Elsio. Crítica à ideia do "caráter patrimonialista" do Estado brasileiro atual. V Simpósio Nacional Estado e Poder. Unioeste - Universidade Estadual do Oeste do Paraná/Campus de Marechal Cândido Rondon. 20 ago. 2015. Disponível em: http://www.historiaepoder.net/index.php.

MIGUEL, Luis F.; MARQUES, Danuza; MACHADO, Carlos. Capital familiar e Carreira Política no Brasil: gênero, partido e Região nas treajetórias para a Câmara dos Deputados. Rio de Janeiro, DADOS-Revista de Ciências Sociais, vo. 58, n. 3, 2015, p. 721-747. 


\section{SEMINÁRIO DE PESQUISA EM CIÊNCIAS HUMANAS - SEPECH \\ Humanidades, Estado e desafios didático-científicos \\ Londrina, 27 a 29 de julho de 2016}

NICOLAU, Jairo. A participação eleitoral no Brasil. In: VIANNA, Luiz Werneck (org.). A democracia e os três poderes. Belo Horizonte: Ed. UFMG; Rio de Janeiro: IUPERJ/FAPERJ, 2002.

OLIVEIRA, Francisco de. Novo poder econômico gera crise. Entrevista com Francisco de Oliveira. Folha de S. Paulo. 07 mai. 2001, p. A6.

OLIVEIRA, Francisco de. Política numa era de indeterminação: opacidade e reencantamento. In: OLIVEIRA, Francisco de e RIZEK, Cibele Saliba (orgs). A era da indeterminação. São Paulo: Boitempo, 2007.

OLIVEIRA, Francisco de. $\mathrm{O}$ apodrecimento da beleza. In: http://www2.fpa.org.br/portal/modules/news/article.php?storyid=1590. Acesso em: 08/06/2009.

OLIVEIRA, Francisco de. Adeus às oligarquias? Disponível em: http:www.teoriaedebate.org.br/materiais/nacional/adeus-oligarquias?page=full. Acesso em: $15 / 04 / 2014$.

REGO,José Márcio e MORAES, Rosa Maria (orgs.). Economia brasileira. São Paulo: Saraiva, 2006.

SAES, Décio. República do capital: capitalismo e processo político no Brasil. São Paulo: Boitempo, 2001.

SAES, Décio. Uma interpretação marxista da evolução do Estado brasileiro. In: COSTA, Silvio (org). Concepções e formação do Estado brasileiro. São Paulo: A. Garibaldi/Universidade Católica de Goiás, 2004.

SANTOS, Wanderley Guilherme dos. A universalização da democracia. In: BENEVIDES, Maria V, KERCHE, Fábio, VANNUCHI, Paulo (orgs.). Reforma política e cidadania. São Paulo: Ed. Fundação Perseu Abramo, 2003.

SANTOS, Wanderley Guilherme dos. O ex-leviatã brasileiro: do voto disperso ao clientelismo concentrado. Rio de Janeiro: Civilização Brasileira, 2006.

SCHOENSTER, Lauren. Clãs políticos seguem dominando Congresso na próxima Legislatura. Disponível em: http://www.transparencia.org.br/publicacoes. Acesso em: 20/04/2016.

TEIXEIRA, Rodrigo Alves e PINTO, Eduardo Costa. A economia política dos governos FHC, Lula e Dilma: dominância financeira, bloco no poder e desenvolvimento econômico. Campinas, Economia e Sociedade, v. 21, dez. 2012, p. 909-941. 